REVIEW

\title{
Chromosome 6p amplification and cancer progression
}

\author{
Gda C Santos, M Zielenska, M Prasad, J A Squire
}

J Clin Pathol 2007;60:1-7. doi: 10.1136/icp.2005.034389

Chromosomal imbalances represent an important mechanism in cancer progression. A clear association between DNA copynumber aberrations and prognosis has been found in a variety of tumours. Comparative genomic hybridisation studies have detected copy-number increases affecting chromosome $6 p$ in several types of cancer. A systematic analysis of large tumour cohorts is required to identify genomic imbalances of $6 p$ that correlate with a distinct clinical feature of disease progression. Recent findings suggest that a central part of the short arm of chromosome $6 p$ harbours one or more oncogenes directly involved in tumour progression. Gains at $6 p$ have been associated with advanced or metastatic disease, poor prognosis, venous invasion in bladder, colorectal, ovarian and hepatocellular carcinomas. Copy number gains of $6 p$ DNA have been described in a series of patients who presented initially with follicle centre lymphoma, which subsequently transformed to diffuse large B cell lymphoma. Melanoma cytogenetics has consistently identified aberrations of chromosome 6, and a correlation with lower overall survival has been described. Most of the changes observed in tumours to date map to the 6p21-p23 region, which encompasses approximately half of the genes on all of chromosome 6 and one third of the number of CpG islands in this chromosome. Analyses of the genes that cluster to the commonly amplified regions of chromosome $6 p$ have helped to identify a small number of molecular pathways that become deregulated during tumour progression in diverse tumour types. Such pathways offer promise for new treatments in the future.

See end of article for authors' affiliations

Correspondence to: J A Squire, Ontario Cancer Institute, Princess Margaret Hospital, Room 9-717, 610 University Avenue, Toronto, Ontario, Canada M5G 2M9; jeremy.squire@utoronto.ca

Accepted 18 May 2006 Published Online First 21 June 2006
A bnormalities of chromosome number leading to aneuploidy are the most common cytogenetic aberrations in cancer. Both genomic and cytogenetic analyses of different types of tumours have shown recurrent DNA copy-number increases associated with progression. A clear association between DNA copynumber aberrations and prognosis has been found in a variety of tumours. ${ }^{1}$

Partial or whole gain of $6 \mathrm{p}$ is much more common than loss. Molecular cytogenetic analysis of chromosome $6 \mathrm{p}$ has shown three modes of $6 \mathrm{p}$ gain:

1 . The most frequent mechanism for generating $6 \mathrm{p}$ gain is the formation of an isochromosome, in which centromeric misdivision leads to triplication of $6 \mathrm{p}$ and monosomy of $6 \mathrm{q} ;$

2. Acquisition of an unbalanced chromosome translocation can also lead to partial or complete $6 \mathrm{p}$ gain; and
3. Focal amplification of a discrete region of $6 p$ typically involves a much larger copy number increase $(>5$-fold $)$.

The last mechanism of gain may involve the formation of double minute chromosomes or homogeneous staining regions.

Genomic imbalance can be detected and mapped by comparative genomic hybridisation $(\mathrm{CGH})$. This method has been used to detect copy-number increases on chromosome $6 \mathrm{p}$ in several human neoplasias, ${ }^{3-7}$ suggesting that this region may contain genes involved directly or indirectly in the pathogenesis and pathways of cancers. This review focuses on gains and amplifications that have been established to be recurrent for chromosome $6 p$ in different classes of solid tumours (fig 1 and table 1), with emphasis on the most commonly amplified genomic interval of 6p21-p23. Such observations are strongly suggestive that this central part of the short arm of chromosome $6 p$ harbours one or more oncogenes directly involved in tumour progression.

\section{CARCINOMAS}

In carcinomas, there is a general association between gains of $6 p$ and tumour progression. In bladder carcinomas, gains of $6 p$ have been reported in invasive bladder tumours, present in $7-55 \%$ of patients. ${ }^{8-15}$ Significant associations have been found between 6p22 gain and high histological grade, ${ }^{16}$ high tumour cell proliferative activity $^{14}$ and metastases at initial presentation, ${ }^{16}$ suggesting that acquisition of $6 p$ gain may confer a growth advantage and lead to disease progression.

As in advanced stages of transitional cell carcinomas in vivo, gains and amplifications of $6 \mathrm{p}$ were often found in transitional cell carcinoma lines with a common region of amplification at the 6p21.3-p23 locus. ${ }^{17}$ Over-representation of 6 p22 was the only individual change that was significantly linked to high tumour grade in a series of 54 pTl urinary bladder carcinomas. The risk of progression was significantly associated with the number of deletions, but not with the number of gains. ${ }^{18}$ Moreover, gain at chromosome 6 p22-p23 was noted in two patients with metastasis at diagnosis among pTa, pTl and pT2-T4G3 tumours and gains of $6 \mathrm{p}$ and $10 \mathrm{p}$ were more frequent in pTlG3 in comparison to pTlG2 tumours. ${ }^{16}$ In highstage lesions 6p22 gains occurred as late events, ${ }^{19}$ and this gain was the only CGH change strongly associated to a high proliferative activity in the

Abbreviations: $\mathrm{BCC}$, basal cell carcinoma; $\mathrm{CGH}$, comparative genomic hybridisation; CRC, colorectal carcinoma; HCC, hepatocellular carcinoma 

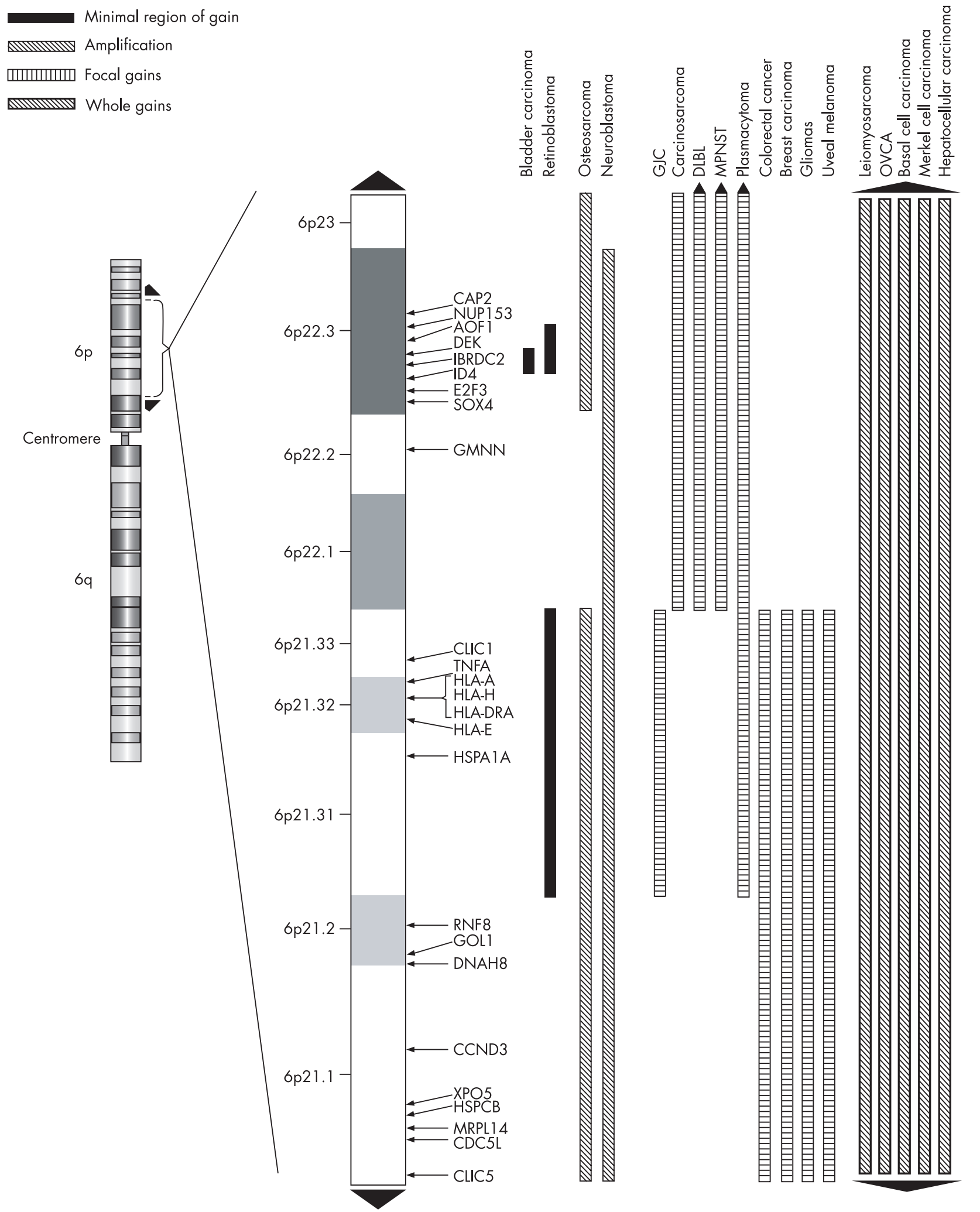

Figure 1 A map of the 6p21-p23 cytobands showing regions of gains and amplifications for specific tumours with genes that were previously published. The black up arrow indicates gain/amplification to the pter and the black down arrow indicates gain/amplification to the centromere. The solid black bar indicates the minimal region of gain; the white bar with black hashed lines indicates a region of amplification; the white bar with black vertical lines indicates a focal gain; and the back bar with white hashed lines indicates a region of gain for the whole 6p arm. 
Table 1 Tumours with 6p21-p23 gain or amplification

\begin{tabular}{|c|c|c|c|}
\hline Type of tumour & Number of tumours & $\begin{array}{l}\text { Tumours with gain in } \\
6 p 21-p 23(\%)\end{array}$ & $\begin{array}{l}\text { Tumours with amplification in } \\
6 p 21-p 23(\%)\end{array}$ \\
\hline \multicolumn{4}{|l|}{ Carcinomas* } \\
\hline Hepatocellular carcinoma & 409 & 22.61 & 0.20 \\
\hline Merkel cell carcinoma & 48 & 27.10 & 2.10 \\
\hline Basal cell carcinoma & 16 & 40.30 & 0.00 \\
\hline Ovarian serous carcinoma & 56 & 28.60 & 0.00 \\
\hline Transitional cell carcinoma & 133 & 9.68 & 0.51 \\
\hline \multicolumn{4}{|l|}{ Lymphoid tumours } \\
\hline Large B cell lymphoma & 360 & 8.36 & 0.07 \\
\hline Plasmacytoma & 21 & 22.76 & 0.00 \\
\hline \multicolumn{4}{|l|}{ Sarcomas } \\
\hline Osteosarcoma & 137 & 33.19 & 3.39 \\
\hline Malignant peripheral nerve sheath & 70 & 23.93 & 0.00 \\
\hline Leiomyosarcoma & 136 & 9.98 & 1.64 \\
\hline Melanomas & 91 & 31.78 & 0.00 \\
\hline Retinoblastoma & 133 & 39.36 & 10.50 \\
\hline Glioblastoma & 108 & 4.60 & 0.90 \\
\hline Neuroblastoma & 303 & 22.10 & 0.17 \\
\hline Carcinosarcoma & 23 & 21.70 & 6.31 \\
\hline
\end{tabular}

*This site does not currently allow the determination of the level of imbalance in a subset of breast and colon carcinomas.

Summary of genomic imbalance datasets from Progenetix (http://www.progenetix.com).

tumour cells and independent of grade and stage of the tumour. ${ }^{14}$

In small-cell carcinomas, which represent a rare histological subtype of urinary bladder cancer, gains of DNA sequences were most prevalent at $8 \mathrm{q}, 5 \mathrm{p}, 6 \mathrm{p}$ and $20 \mathrm{q} \cdot{ }^{20}$ High-level amplifications were detected most often at 6p22.3 (E2F3) and at four other genomic locations in 41 primary bladder tumours. Interestingly, there was a significant complementary association between gain of cyclin DI at $1 \mathrm{lq13}$ and gain of E2F3, although there was no significant relationship between copy number changes and tumour stage or grade. ${ }^{21}$ Using quantitative multiplex polymerase chain reaction to study DNA from 59 bladder tumours, the focal region of genomic gain on 6 p22 was mapped to a minimal region, spanning a genomic distance of $0.5 \mathrm{Mb} .{ }^{15}$ The E2F3 gene has been recently implicated as the target of 6 p22 genomic gain in bladder cancer. ${ }^{22}{ }^{23}$ In a study using bladder tumour-derived cell lines, NM 017774 showed an expression related to the $6 \mathrm{p} 22.3$ amplicon. ${ }^{\overline{24}}$ A recent paper reported overexpression of ID4 gene, which maps between $E 2 F 3$ and $D E K$, in bladder cancer. ${ }^{25}$

Increased copy number of chromosome arm $6 \mathrm{p}$ has been associated with advanced stages of colorectal cancer (Dukes' stage D) and metastasis. ${ }^{7}$ In a recent CGH study on liver metastasis of colorectal carcinoma (CRC), gain in $6 \mathrm{p} 21$ was found in $41 \%$ of the patients. Taken together, both these observations suggest that acquisition of $6 \mathrm{p}$ gain may be contributing to progression in colorectal cancer, and that part of the short arm of this chromosome might harbour one or more oncogenes. ${ }^{26}$ A subtractive CGH analysis using paired samples from 20 patients with CRC with primary tumours and synchronous or metachronous liver metastases detected frequent gains in DNA copy number at 6p. Analysis of 11 CRC cell lines using array-based CGH showed one $6 \mathrm{p}$ candidate gene, cyclin D3, which was significantly up regulated by quantitative reverse transcriptase-polymerase chain reaction in liver-metastatic lesions compared with primary lesions.

DNA amplification data from $\mathrm{CGH}$ and serial analyses of gene expression showed several chromosomal arms-for example, that chromosome 6 had frequent DNA amplifications that showed frequent changes in gene expression in gastroesophageal junction carcinomas. Despite the relatively large DNA amplification regions, overexpressed genes often mapped and clustered to small chromosomal regions at early-replicating bands such as 1921.3 (nine genes), $6 p 21.3$ (five genes) and $17 q 21$ (eight genes). ${ }^{27}$

CGH studies have shown that the most frequent gains in hepatocellular carcinoma (HCC) occurred at 8q, 1q, 3q, 6p and 17q. ${ }^{28-30}$ Chromosomal aberrations investigated in HCC cell lines that had hepatitis $\mathrm{B}$ virus integration showed chromosomal gains at $6 \mathrm{p} .^{31}$ Amplifications at $\mathrm{lq}$ and $6 \mathrm{p}$ appeared to be independent factors for venous invasion in HCC. ${ }^{32}$ Significantly, a recent study described that physical clusters of two or more genes within predefined distance thresholds were detected non-randomly on chromosomal regions lq, 6p, 8q, 20q and Xq, indicating that HCC-related genes are physically clustered at specific chromosomal locations. ${ }^{33}$ A previous study that mapped genes overexpressed in HCC to chromosomal locations found 13 regions of frequent cytogenetic change, including $6 \mathrm{p}$ gain..$^{34} \mathrm{~A}$ recent explorative CGH meta-analysis of HCC showed that the most marked amplifications were present at $1 \mathrm{q}(57.1 \%), 8 \mathrm{q}$ (46.6\%), 6p (22.3\%) and 17q (22.2\%). ${ }^{35}$

In breast carcinomas, genomic imbalances with statistical significance were observed in poorly differentiated (G3) and oestrogen receptor negative tumours, including one region of $6 \mathrm{p}$ gain. ${ }^{36}$ One of the most frequent chromosomal aberration found in patients with high-risk stage II/III breast cancer was 6p gain. ${ }^{37}$ Gain on 6 p21 was identified in 14 of 31 (45\%) formalinfixed and paraffin-wax-embedded primary advanced breast tumours analysed by microarray-based CGH.

Recurrent gains of chromosome 6 have been detected in Merkel cell carcinomas. ${ }^{6}{ }^{38}$ Although no significant correlation between genomic aberrations and clinicopathological factors was shown, primary tumours expressing changes in DNA were predominantly distinguished in large Merkel cell carcinomas, and risk of metastatic dissemination was threefold compared with tumours without chromosomal changes. ${ }^{38}$

In basal cell carcinoma (BCC) of the skin, recurrent changes were observed in $47 \%$ of the patients at $6 \mathrm{p} 21$-pter. Interestingly, it was found that regional gain of $9 p$ was strongly associated with $6 p$ gain; however, no correlation between this association and clinical or histological appearance was observed in these patients. ${ }^{5}$ These results correlate with a previous study that identified clonal trisomy of chromosome 6 in BCC direct preparations by conventional cytogenetics and fluorescent in 
situ hybridisation analysis. No correlations between the BCC cytogenetic results and clinical parameters such as site, age, sex and recurrence rate have been shown. ${ }^{39}$

Gains of $6 p$ were more common in stage IIIc than in stage IIIa+b ovarian serous papillary adenocarcinomas. ${ }^{40}$ A study of ovarian epithelial tumours using CGH found that high-grade serous carcinomas had more than twice as much chromosomal imbalance as low-grade serous carcinomas and also had pronounced changes. Overlapping changes occurring in serous and non-serous carcinomas were gains on $3 q$ and $6 p$, as well as losses on 4q. Among other chromosomal imbalances, $6 \mathrm{p}$ gain was associated with poor prognosis of ovarian carcinomas, ${ }^{41}$ and 6p22.1-p21.2 was one of several regions associated with acquisition to drug resistance in serous carcinomas. ${ }^{42}$

\section{LYMPHOID TUMOURS}

Amplification of the 6p21 locus has been documented in nonHodgkin's lymphoma. Among 27 specimens of patients with plasmacytoma, $25 \%$ of the specimens showed gain of $6 \mathrm{p}$, with a minimal overlapping region at 6 p21.3-pter. ${ }^{43}$ Acquisition of $6 p$ has a significantly higher frequency in large B cell tumours, and it was an independent prognostic factor with losses of 11q21q23.1 and $17 \mathrm{p}^{44}$ In another study of diffuse large B cell lymphoma with primary tumours and recurrent tumours excised after chemotherapy or radiotherapy, $21 \%$ showed $6 p$ gain with minimal common regions at $6 \mathrm{p} 22$-pter. High-level amplifications were observed at 6p23-pter and occurred only in different recurrent tumours. ${ }^{45}$ In a series of 23 patients, 21 showed genomic changes, with a mean value of 11 aberrations/ sample (range 2-29). Among other regions, the minimal common region of 6p22-pter was most frequently gained. ${ }^{46}$ In non-Hodgkin's lymphomas, it has been shown and suggested that gains on $6 \mathrm{p}$ among other changes may be important in the transformation from low-grade to high-grade disease. ${ }^{47}$ Recently, over-representation of 6p12.3-p21 among other genomic aberrations was reported in samples from patients who presented initially with follicle centre lymphoma, which subsequently transformed to diffuse large B cell lymphoma as measured by array $\mathrm{CGH}^{48} \mathrm{~A}$ subset of genes that mapped to locations of gain or amplification exhibited coordinated increase or decrease of expression. ${ }^{49}$

\section{MELANOMAS}

Melanoma cytogenetics has consistently identified aberrations of chromosome 6 as the most common change. CGH analyses have identified recurrent chromosomal abnormalities at several locations including $6 \mathrm{p}$ gain in choroid and ciliary body melanomas $(30-85 \%),{ }^{50-56}$ in acral and superficial, ${ }^{57}{ }^{58}$ and in sinonasal mucosal melanomas (93\%). Gain of $6 \mathrm{p}$ occurred frequently in combination with a loss of copy number or a normal copy number of the opposite chromosome arm, suggesting isochromosome formation. ${ }^{59}$

Changes on $6 \mathrm{p}$, detected by microsatellite analysis in 15 of 30 $(50 \%)$ patients with uveal melanoma, were preferentially observed in tumours without chromosome 3 changes. ${ }^{53}$ Another study of 12 patients with uveal melanomas showed under-representation of chromosome 3 exclusively in tumours with ciliary body involvement, whereas anomalies of chromosome 6 were described only in pure choroidal melanomas. ${ }^{60}$ Recently, an inverse relationship between monosomy 3 and gain of $6 \mathrm{p}$ has been detected in uveal and in cutaneous melanomas. ${ }^{56}{ }^{61}$ A CGH study using 16 primary and 12 metastatic melanoma specimens showed that the pattern of chromosomal aberrations was similar in the two subgroups. The most frequent change was gain of $6 \mathrm{p}$ in $63 \%$ of primary and in $50 \%$ of metastatic tumours. ${ }^{2}$ Another CGH study has shown that tumours with $6 \mathrm{p}$ or lq gain had lower overall survival in comparison to those without gain, thus implying that acquisition of $6 \mathrm{p}$ or lq gain may confer prognostic differences. ${ }^{63}$

\section{SARCOMAS}

Gain of $6 p$ is one of the most frequent chromosomal change in osteosarcomas. ${ }^{64-68}$ A CGH study with 31 primary high-grade osteosarcomas found gain of $6 \mathrm{pl2}-\mathrm{p} 21.3$ in $10(32 \%)$ patients. Other frequent DNA sequence copy-number changes were described, without prognostic significance, affecting chromosomal regions not previously associated with tumorigenesis of osteosarcomas. ${ }^{69}$ The same authors described an association between copy-number increase at $6 p$ and reduced overall and distant disease-free survival. ${ }^{70}$ In another study chromosome 6 was involved in 37 rearrangements, of which nine were mapped to $6 \mathrm{p} 12-\mathrm{p} 21 .^{67}$ The same panel of 25 tumours showed amplification at $6 \mathrm{pl2}-\mathrm{p} 2 \mathrm{l}$ in seven tumours. Three nonoverlapping BAC clones were identified within a $6 \mathrm{p}$ amplicon and several genes present in these clones. In this study, amplification of $6 \mathrm{p} 12-\mathrm{p} 21$ appeared to be significant and early event in the pathogenesis of osteosarcomas as it was observed in all specimen types: biopsy, definitive surgery and metastatic lesion. These chromosomal bands were also involved in the chromosomal rearrangements identified by SKY. These findings suggested the presence of oncogenes at $6 \mathrm{pl} 2-\mathrm{p} 2 \mathrm{l}$ whose overexpression may lead to the malignant phenotype in osteosarcomas. On the basis of the combined array CGH and fluorescent in situ hybridisation analysis, the same group suggested CDCSL, HSPCB, NFKBIE, HGNC and MRPLI4 as the target genes from the $6 \mathrm{p} 12-\mathrm{p} 21$ amplicon (fig l) ${ }^{68}$ A microarray CGH study showed that 6 of 9 osteosarcomas with a $6 p$ gain contained the common region of gain of band $6 \mathrm{pl} 2 .{ }^{66}$ Focal amplifications occurred at 6p22.3-p25.1, 6p21 and 6p12; the broader regions of gain seen at $6 \mathrm{p} 22.3-\mathrm{p} 24.2$ and $6 \mathrm{p} 21.2-\mathrm{p} 21.31$ were consistent with a potential role for the breakage fusion bridge cycle in generation of amplification of $6 \mathrm{p}$ in one osteosarcoma cell line. ${ }^{71}$ In all, 10 of 23 patients showed gain but not high-level amplifications of 6p22-pter in a CGH study of malignant peripheral nerve sheath tumours, although this change did not have any prognostic relevance. ${ }^{72}$ High-level gain of DNA copy number was detected in $6 p$ and $17 p$ in a study of 17 leiomyosarcomas. $^{73}$

\section{RETINOBLASTOMA}

Gains of the entire chromosome arm $6 p$ have been reported very frequently in retinoblastoma. ${ }^{24-77}$ Interestingly, by far the most frequent mechanism of gain is by acquisition of an isochromosome of 6 p. $^{24}{ }^{78-80}$ Karyotype studies showed small additional fragments of $6 \mathrm{p}$, often including the distal segment $6 \mathrm{p} 25-\mathrm{p} 22$. This led to the assumption that increased copy number of genes localised in this region of $6 \mathrm{p}$ may confer a selective growth advantage to retinoblastoma cells. ${ }^{81}$ One of the most frequent imbalance observed in a series of primary retinoblastoma (13/24) cases was $6 \mathrm{p}$ gain, and no evident correlation was found between any of the imbalances identified and either the differentiation or the histoprognostic risk. ${ }^{74}$ Gains at $6 p$ were also identified in another CGH study in 11 $(42.3 \%)$ tumours, suggesting that $6 \mathrm{p} 22-\mathrm{p} 25$ might be a candidate chromosome region for containing presumptive retinoblastoma growth-promoting genes. ${ }^{75}$ Subsequent CGH results have shown that the common region of gain maps to chromosome band 6p22. ${ }^{4}$ Using quantitative multiplex polymerase chain reaction, the same group narrowed down the region to a $0.6-\mathrm{Mb}$ region spanning the UniSTS markers X64229 and WI-19208. ${ }^{82}$ Recently, it was found that only three of seven genes, DEK, NUP153 and E2F3, in this region analysed using real-time reverse transcriptase-polymerase chain reaction are overexpressed in retinoblastoma tumours and cell lines with 
documented genomic gain of 6p22. E2F3 and DEK mRNA overexpression was always associated with protein overexpression of primary tumours relative to the adjacent normal retina. E2F3 was strongly expressed in actively proliferating cells, whereas DEK was overexpressed in all tumour cells. It was concluded that both $E 2 F 3$ and $D E K$ were promising targets of the 6 p22 genomic gain in retinoblastoma. ${ }^{83}$ Another study narrowed the minimal region of gain on $6 p$ to the band $6 \mathrm{p} 22.3$ using a panel of retinoblastomas and retinoblastoma cell lines. The data indicated that the minimal region of chromosomal imbalance in 6p22.3 includes the NUP 153, KIF 13A, TPMT, DEK, ID4, E2F3 and TTRAP genes. Copy number gains were most consistently identified in the region containing the $D E K$ and $E 2 F 3$, thus suggesting these genes as potential targets of $6 \mathrm{p}$ gains. ${ }^{84} \mathrm{~A}$ high-resolution matrix-CGH analysis performed on a series of 17 primary retinoblastomas and 4 retinoblastoma cell lines showed on $6 \mathrm{p}$ a minimally overlapping gained region at $6 \mathrm{p} 21.31-\mathrm{p} 21.33$ that was $2.31 \mathrm{Mb}$ in size and suggested the tumour necrosis factor $\alpha$ as a potential candidate gene. ${ }^{77}$

\section{OTHER TUMOURS}

One frequent over-representation was seen at 6p (minimal region of overlap in six patients, 6p22-p23) in a CGH analysis of 19 uterine and extrauterine carcinosarcomas. Amplifications of $6 \mathrm{p}$ were detected in two patients. ${ }^{85}$ Amplification and overexpression of cyclin D3 gene located in the $6 \mathrm{p} 21$ region has been detected in glioblastoma cell lines. ${ }^{86}$ It was suggested that the increased amounts of cyclin D3 caused by gene amplification could be involved in the development or progression of that glioblastoma. ${ }^{46}$ Common gains observed in 29 neuroblastomas were on chromosomes 7, 6 and 18. High-level amplifications were detected at 2p23-p25 (MYCN region), at 4q33-q35 and at $6 \mathrm{p} 11-\mathrm{p} 22 .{ }^{87}$ A CGH analysis of clinically non-progressing stage 4s neuroblastomas showed a high rate of whole-chromosome aberrations $(73.4 \%)$, with an over-representation of chromosomes 2, 6, 7, 12, 13, 17 and 18 and an under-representation of chromosomes $3,4,11$ and $14 .^{88}$

\section{CONCLUSIONS AND FUTURE PROSPECTS}

CGH studies have identified frequent amplifications and rearrangements involving $6 \mathrm{p}$ in a wide variety of different types of tumours. These observations suggest that genes more generally associated with tumour progression may map to this genomic location. In all, 624 genes are seen in the $33-\mathrm{Mb}$ region of 6p21-23, which represents about half of the genes on whole chromosome 6 (table 2). Several lines of evidence presented in this review implicate that one or more putative oncogenes may underlie the association between gain of $6 \mathrm{p}$ and tumour progression. The genomic architecture of the $6 \mathrm{p}$ region is noteworthy. The number of $\mathrm{CpG}$ islands in the $6 \mathrm{p} 2 \mathrm{l}-\mathrm{p} 23$ region corresponds to one third of the number of $\mathrm{CpG}$ islands in

Table 2 Genomic features of 6p21-p23

\begin{tabular}{lcc}
\hline & \multicolumn{2}{l}{ Genomic features of:* } \\
\cline { 2 - 3 } & $\begin{array}{l}\text { 6p21-p23 } \\
\text { region }\end{array}$ & Chromosome 6 \\
\hline Size of the region (Mb) & 33 & 171 \\
Number of genes & 624 & 1394 \\
Repeats & 59854 & 265300 \\
CpG island & 5508 & 17622 \\
Variations (SNPs) & 141464 & 601204 \\
OMIM morbid & 62 & 121 \\
Mitelman breakpoint elements & 78 & 665 \\
\hline SNP, single nucleotide polymorphism. & \\
*Data acquired from hitp://www.ncbi.nlm.nih.gov/mapview/.
\end{tabular}

Take-home messages

- A clear association between DNA copy-number aberrations and prognosis has been found in a variety of tumours. CGH studies have identified frequent amplifications and rearrangements involving $6 p$ in different types of tumours.

- Several lines of evidence presented in this review suggest that a part of the short arm of chromosome 6p harbours one or more oncogenes directly involved in tumour progression.

- Some tumours described in this review present concordant genomic changes associated with 6p gain showing possible cytogenetic pathways. The application of systematic array CGH studies can help to show correlations and linked behaviour among genes that cluster to chromosome 6p and other specific regions. Such an approach will unravel different pathways for an improved understanding of tumour progression.

chromosome 6. Recently, it has been shown that gene density, guanine-cytosine content and replication timing all co-correlate strongly with transcriptional activity, thus confirming that expressed genes tend to be replicated early in the $S$ phase. ${ }^{89}$

In solid tumours, significantly high levels of chromosome abnormalities have been detected, but distinction between critical and consequential events has been a major challenge. It has been proposed that correlations between imbalances would show possible cytogenetic pathways. Some tumours described in this review present concordant genomic changes associated with $6 \mathrm{p}$ gain. In the future, the application of systematic higher resolution array CGH studies will help to show correlations and linked behaviour among genes that cluster to chromosome $6 \mathrm{p}$ and other specific regions, thus unravelling different pathways for an improved understanding of tumour progression. Analysis of the genes that cluster to the commonly amplified regions of chromosome $6 \mathrm{p}$ has helped to identify a small number of molecular pathways that become deregulated during tumour progression in diverse tumour types. ${ }^{21}{ }^{61}$ Identification of such pathways will offer promise for new approaches to treatment in the future.

\section{Authors' affiliations}

G da C Santos, M Prasad, J A Squire, Department of Applied Molecular Oncology, Ontario Cancer Institute, Princess Margaret Hospital, University of Toronto, Toronto, Ontario, Canada

G da C Santos, Department of Pathology, Universidade Federal de Sao Paulo, Sao Paulo, Brazil

G da C Santos, CIHR Molecular Oncologic Pathology Program, Toronto, Ontario, Canada

M Zielenska, J A Squire, Department of Laboratory Medicine and Pathobiology, University of Toronto, Toronto, Ontario, Canada

M Zielenska, Department of Pathology and Laboratory Medicine, The Hospital for Sick Children, Toronto, Ontario, Canada

J A Squire, Department of Medical Biophysics, University of Toronto, Toronto, Ontario, Canada

\section{Competing interests: None declared.}

Funding: GdCS was supported by CAPES - Ministry of Education, Brazil. Financial support for this project was provided by the National Cancer Institute of Canada (NCIC), with funds from the Canadian Cancer Society.

\section{REFERENCES}

1 Pinkel D, Albertson DG. Array comparative genomic hybridization and its applications in cancer. Nat Genet 2005;37(Suppl):S11-17. 
2 Squire J, Phillips RA, Boyce S, et al. Isochromosome 6p, a unique chromosomal abnormality in retinoblastoma: verification by standard staining techniques, new densitometric methods, and somatic cell hybridization. Hum Genet 1984;66:46-53

3 Knuutila S, Bjorkqvist AM, Autio K, et al. DNA copy number amplifications in human neoplasms: review of comparative genomic hybridization studies. Am J Pathol 1998; 152:1 107-23.

4 Chen D, Gallie BL, Squire JA. Minimal regions of chromosomal imbalance in retinoblastoma detected by comparative genomic hybridization. Cancer Genet Cytogenet 2001; 129:57-63.

5 Ashton KJ, Weinstein SR, Maguire DJ, et al. Molecular cytogenetic analysis of basal cell carcinoma DNA using comparative genomic hybridization. J Invest Dermatol 2001;117:683-6.

6 Larramendy ML, Koljonen V, Bohling $T$, et al. Recurrent DNA copy number changes revealed by comparative genomic hybridization in primary Merkel cell carcinomas. Mod Pathol 2004; 17:561-7.

7 Al-Mulla F, Keith WN, Pickford IR, et al. Comparative genomic hybridization analysis of primary colorectal carcinomas and their synchronous metastases. Genes Chromosomes Cancer 1999;24:306-14.

8 Bruch J, Wohr G, Hautmann R, et al. Chromosomal changes during progression of transitional cell carcinoma of the bladder and delineation of the amplified interval on chromosome arm 8q. Genes Chromosomes Cancer 1998;23:167-74.

9 Richter J, Beffa L, Wagner U, et al. Patterns of chromosomal imbalances in advanced urinary bladder cancer detected by comparative genomic hybridization. Am J Pathol 1998;153:1615-21.

10 Hovey RM, Chu L, Balazs M, et al. Genetic alterations in primary bladder cancers and their metastases. Cancer Res 1998;58:3555-60.

$11 \mathrm{Koo}$ SH, Kwon KC, Ihm CH, et al. Detection of genetic alterations in bladder tumors by comparative genomic hybridization and cytogenetic analysis. Cancer Genet Cytogenet 1999;1 10:87-93.

12 Czerniak B, Li L, Chaturvedi V, et al. Genetic modeling of human urinary bladder carcinogenesis. Genes Chromosomes Cancer 2000;27:392-402.

13 Simon R, Burger H, Semjonow A, et al. Patterns of chromosomal imbalances in muscle invasive bladder cancer. Int J Oncol 2000;17:1025-9.

14 Tomovska S, Richter J, Suess K, et al. Molecular cytogenetic alterations associated with rapid tumor cell proliferation in advanced urinary bladde cancer. Int J Oncol 2001;18:1239-44.

15 Evans AJ, Gallie BL, Jewett MA, et al. Defining a $0.5-\mathrm{mb}$ region of genomic gain on chromosome 6p22 in bladder cancer by quantitative-multiplex polymerase chain reaction. Am J Pathol 2004;164:285-93.

16 Prat E, Bernues M, Caballin MR, et al. Detection of chromosomal imbalances in papillary bladder tumors by comparative genomic hybridization. Urology 2001;57:986-92.

17 Bruch J, Schulz WA, Haussler J, et al. Delineation of the 6p22 amplification unit in urinary bladder carcinoma cell lines. Cancer Res 2000;60:4526-30.

18 Richter J, Wagner U, Schraml P, et al. Chromosomal imbalances are associated with a high risk of progression in early invasive $(\mathrm{pT} 1)$ urinary bladder cancer. Cancer Res 1999;59:5687-91.

19 Simon R, Eltze E, Schafer KL, et al. Cytogenetic analysis of multifocal bladder cancer supports a monoclonal origin and intraepithelial spread of tumor cells. Cancer Res 2001:61:355-62.

20 Terracciano L, Richter J, Tornillo L, et al. Chromosomal imbalances in small cell carcinomas of the urinary bladder. J Pathol 1999;189:230-5.

21 Veltman JA, Fridlyand J, Pejavar S, et al. Array-based comparative genomic hybridization for genome-wide screening of DNA copy number in bladder tumors. Cancer Res 2003:63:2872-80.

22 Feber A, Clark J, Goodwin G, et al. Amplification and overexpression of E2F3 in human bladder cancer. Oncogene 2004;23:1627-30.

23 Oeggerli M, Tomovska S, Schraml P, et al. E2F3 amplification and overexpression is associated with invasive tumor growth and rapid tumor cell proliferation in urinary bladder cancer. Oncogene 2004;23:5616-23.

24 Hurst CD, Fiegler $\mathrm{H}$, Carr $\mathrm{P}$, et al. High-resolution analysis of genomic copy number alterations in bladder cancer by microarray-based comparative genomic hybridization. Oncogene 2004;23:2250-63.

25 Wu Q, Hoffmann MJ, Hartmann FH, et al. Amplification and overexpression of the ID4 gene at 6p22.3 in bladder cancer. Mol Cancer 2005;4:16.

26 Diep CB, Parada LA, Teixeira MR, et al. Genetic profiling of colorectal cancer liver metastases by combined comparative genomic hybridization and $\mathrm{G}$ banding analysis. Genes Chromosomes Cancer 2003;36:189-97.

27 Koon N, Zaika A, Moskaluk CA, et al. Clustering of molecular alterations in gastroesophageal carcinomas. Neoplasia 2004;6:143-9.

28 Marchio A, Meddeb M, Pineau P, et al. Recurrent chromosomal abnormalities in hepatocellular carcinoma detected by comparative genomic hybridization. Genes Chromosomes Cancer 1997; 18:59-65.

29 Lin YW, Sheu JC, Huang GT, et al. Chromosomal abnormality in hepatocellular carcinoma by comparative genomic hybridisation in Taiwan. Eur J Cancer 1999; 35:652-8.

30 Chen YJ, Yeh SH, Chen JT, et al. Chromosomal changes and clonality relationship between primary and recurrent hepatocellular carcinoma. Gastroenterology 2000;119:431-40.

31 Hwang HJ, Kim GJ, Lee GB, et al. A comprehensive karyotypic analysis on Korean hepatocellular carcinoma cell lines by cross-species color banding and comparative genomic hybridization. Cancer Genet Cytogenet 2003;141:128-37

32 Pang $\mathrm{A}, \mathrm{Ng} \mathrm{IO}$, Fan ST, et al. Clinicopathologic significance of genetic alterations in hepatocellular carcinoma. Cancer Genet Cytogenet 2003; 146:8-15.
33 Patil MA, Chua MS, Pan KH, et al. An integrated data analysis approach to characterize genes highly expressed in hepatocellular carcinoma. Oncogene 2005;24:3737-47

34 Crawley JJ, Furge KA. Identification of frequent cytogenetic aberrations in hepatocellular carcinoma using gene-expression microarray data. Genome Bio 2002;3:Research0075.1-0075.8.

35 Moinzadeh P, Breuhahn K, Stutzer H, et al. Chromosome alterations in human hepatocellular carcinomas correlate with aetiology and histological graderesults of an explorative CGH meta-analysis. Br J Cancer 2005;92:935-41.

36 Richard F, Pacyna-Gengelbach M, Schluns K, et al. Patterns of chromosomal imbalances in invasive breast cancer. Int J Cancer 2000;89:305-10.

37 Seute A, Sinn HP, Schlenk RF, et al. Clinical relevance of genomic aberrations in homogeneously treated high-risk stage II/III breast cancer patients. Int J Cancer $2001 ; 93: 80-4$

38 Harle M, Arens N, Moll I, et al. Comparative genomic hybridization (CGH) discloses chromosomal and subchromosomal copy number changes in Merke cell carcinomas. J Cutan Pathol 1996;23:391-7.

39 Casalone R, Mazzola D, Righi R, et al. Cytogenetic and interphase FISH analyses of 73 basal cell and three squamous cell carcinomas: different findings in direct preparations and short-term cell cultures. Cancer Genet Cytogenet 2000;1 18:136-43

40 Partheen K, Levan K, Osterberg L, et al. Analysis of cytogenetic alterations in stage III serous ovarian adenocarcinoma reveals a heterogeneous group regarding survival, surgical outcome, and substage. Genes Chromosomes Cancer 2004;40:342-8

41 Hauptmann S, Denkert C, Koch I, et al. Genetic alterations in epithelial ovarian tumors analyzed by comparative genomic hybridization. Hum Pathol 2002;33:632-41.

42 Bernardini $\mathrm{M}$, Lee $\mathrm{CH}$, Beheshti $\mathrm{B}$, et al. High-resolution mapping of genomic imbalance and identification of gene expression profiles associated with differential chemotherapy response in serous epithelial ovarian cancer Neoplasia 2005;7:603-13.

43 Aalto $\mathrm{Y}$, Nordling S, Kivioja AH, et al. Among numerous DNA copy number changes, losses of chromosome 13 are highly recurrent in plasmacytoma. Genes Chromosomes Cancer 1999;25:104-7.

44 Stokke T, DeAngelis P, Smedshammer L, et al. Loss of chromosome 11 q21-23.1 and 17p and gain of chromosome $6 p$ are independent prognostic indicators in Bcell non-Hodgkin's lymphoma. Br J Cancer 2001;85:1900-13.

45 Monni O, Joensuu H, Franssila K, et al. DNA copy number changes in diffuse large B-cell lymphoma-comparative genomic hybridization study. Blood 1996;87:5269-78

46 Kuchiki H, Saino M, Nobukuni T, et al. Detection of amplification of a chromosomal fragment at 6 p21 including the cyclin D3 gene in a glioblastoma cell line by arbitrarily primed polymerase chain reaction. Int J Cancer 2000;85:113-16.

47 Hough RE, Goepel JR, Alcock HE, et al. Copy number gain at 12q12-14 may be important in the transformation from follicular lymphoma to diffuse large $B$ cell lymphoma. Br J Cancer 2001;84:499-503.

48 Martinez-Climent JA, Alizadeh AA, Segraves R, et al. Transformation of follicular lymphoma to diffuse large cell lymphoma is associated with a heterogeneous set of DNA copy number and gene expression alterations. Blood 2003;101:3109-17.

49 Lossos IS, Alizadeh AA, Diehn M, et al. Transformation of follicular lymphoma to diffuse large-cell lymphoma: alternative patterns with increased or decreased expression of c-myc and its regulated genes. Proc Natl Acad Sci USA 2002:99:8886-91.

50 Gordon KB, Thompson CT, Char DH, et al. Comparative genomic hybridization in the detection of DNA copy number abnormalities in uveal melanoma. Cancer Res 1994:54:4764-8.

51 Speicher MR, Prescher G, du Manoir S, et al. Chromosomal gains and losses in uveal melanomas detected by comparative genomic hybridization. Cancer Res 1994;54:3817-23.

52 Aalto Y, Eriksson L, Seregard S, et al. Concomitant loss of chromosome 3 and whole arm losses and gains of chromosome 1, 6, or 8 in metastasizing primary uveal melanoma. Invest Ophthalmol Vis Sci 2001;42:313-17.

53 Tschentscher F, Prescher G, Zeschnigk $M$, et al. Identification of chromosomes 3 , 6 , and 8 aberrations in uveal melanoma by microsatellite analysis in comparison to comparative genomic hybridization. Cancer Genet Cytogenet 2000; 122:13-17.

54 Vajdic CM, Hutchins AM, Kricker A, et al. Chromosomal gains and losses in ocular melanoma detected by comparative genomic hybridization in an Australian population-based study. Cancer Genet Cytogenet 2003;144:12-17.

55 Erol N, Oner U, Artan S, et al. Chromosomal abnormalities, p53 and Bcl-2 expression and clinical outcome in choroidal melanoma. Melanoma Res 2004:14:473-8.

56 Hughes S, Damato BE, Giddings I, et al. Microarray comparative genomic hybridisation analysis of intraocular uveal melanomas identifies distinctive imbalances associated with loss of chromosome 3. Br J Cancer 2005;63:10-19.

57 Bastian BC, Kashani-Sabet M, Hamm H, et al. Gene amplifications characterize acral melanoma and permit the detection of occult tumor cells in the surrounding skin. Cancer Res 2000;60:1968-73.

58 Bastian BC, Olshen AB, LeBoit PE, et al. Classifying melanocytic tumors based on DNA copy number changes. Am J Pathol 2003;163:1765-70.

59 van Dijk M. Sprenger S, Rombout $P$, et al. Distinct chromosomal aberrations in sinonasal mucosal melanoma as detected by comparative genomic hybridization. Genes Chromosomes Cancer 2003;36:151-8.

60 Prescher G, Bornfeld N, Friedrichs W, et al. Cytogenetics of twelve cases of uveal melanoma and patterns of nonrandom anomalies and isochromosome formation. Cancer Genet Cytogenet 1995;80:40-6. 
61 Hoglund M, Gisselsson D, Hansen GB, et al. Dissecting karyotypic patterns in malignant melanomas: temporal clustering of losses and gains in melanoma karyotypic evolution. Int J Cancer 2004; 108:57-65.

62 Balazs M, Adam Z, Treszl A, et al. Chromosomal imbalances in primary and metastatic melanomas revealed by comparative genomic hybridization. Cytometry 2001;46:222-32

63 Namiki T, Yanagawa S, Izumo T, et al. Genomic alterations in primary cutaneous melanomas detected by metaphase comparative genomic hybridization with laser capture or manual microdissection: 6p gains may predict poor outcome. Cancer Genet Cytogenet 2005;157:1-11.

64 Ozaki T, Schaefer KL, Wai D, et al. Genetic imbalances revealed by comparative genomic hybridization in osteosarcomas. Int J Cancer 2002;102:355-65.

65 Forus A, Weghuis DO, Smeets D, et al. Comparative genomic hybridization analysis of human sarcomas: II. Identification of novel amplicons at $6 p$ and $17 p$ in osteosarcomas. Genes Chromosomes Cancer 1995;14:15-21.

66 Squire JA, Pei J, Marrano P, et al. High-resolution mapping of amplifications and deletions in pediatric osteosarcoma by use of $\mathrm{CGH}$ analysis of cDNA microarrays. Genes Chromosomes Cancer 2003;38:215-25.

67 Lau CC, Harris CP, Lu XY, et al. Frequent amplification and rearrangement of chromosomal bands $6 \mathrm{p} 12-\mathrm{p} 21$ and 17p11.2 in osteosarcoma. Genes Chromosomes Cancer 2004;39:11-21.

68 Man TK, Lu XY, Jaeweon K, et al. Genome-wide array comparative genomic hybridization analysis reveals distinct amplifications in osteosarcoma. BMC Cancer 2004;4:45.

69 Tarkkanen M, Elomaa I, Blomqvist C, et al. DNA sequence copy number increase at $8 \mathrm{q}$ : a potential new prognostic marker in high-grade osteosarcoma. Int J Cancer 1999;84:114-21.

70 Tarkkanen M, Kiuru-Kuhlefelt S, Blomqvist C et al. Clinical correlations of genetic changes by comparative genomic hybridization in Ewing sarcoma and related tumors. Cancer Genet Cytogenet 1999;1 14:35-41

71 Lim G, Karaskova J, Beheshti B, et al. An integrated mBAND and submegabase resolution tiling set (SMRT) CGH array analysis of focal amplification, microdeletions, and ladder structures consistent with breakage-fusion-bridge cycle events in osteosarcoma. Genes Chromosomes Cancer 2005;42:392-403.

72 Schmidt H, Wurl P, Taubert H, et al. Genomic imbalances of $7 p$ and $17 q$ in malignant peripheral nerve sheath tumors are clinically relevant. Genes Chromosomes Cancer 1999:25:205-11.

73 Hu J, Rao UN, Jasani S, et al. Loss of DNA copy number of $10 \mathrm{q}$ is associated with aggressive behavior of leiomyosarcomas: a comparative genomic hybridization study. Cancer Genet Cytogenet 2005;161:20-7.

74 Mairal A, Pinglier E, Gilbert E, et al. Detection of chromosome imbalances in retinoblastoma by parallel karyotype and CGH analyses. Genes Chromosomes Cancer 2000;28:370-9.
75 Herzog S, Lohmann DR, Buiting K, et al. Marked differences in unilateral isolated retinoblastomas from young and older children studied by comparative genomic hybridization. Hum Genet 2001;108:98-104.

76 Lillington DM, Kingston JE, Coen PG, et al. Comparative genomic hybridization of 49 primary retinoblastoma tumors identifies chromosomal regions associated with histopathology, progression, and patient outcome. Genes Chromosomes Cancer 2003;36:121-8

77 Zielinski B, Gratias S, Toedt G, et al. Detection of chromosomal imbalances in retinoblastoma by matrix-based comparative genomic hybridization. Genes Chromosomes Cancer 2005;43:294-301.

78 Potluri VR, Helson L, Ellsworth RM, et al. Chromosomal abnormalities in human retinoblastoma. A review. Cancer 1986;58:663-71.

79 Horsthemke B, Greger V, Becher R, et al. Mechanism of $\mathrm{i}(6 \mathrm{p})$ formation in retinoblastoma tumor cells. Cancer Genet Cytogenet 1989;37:95-102.

80 Cano J, Oliveros O, Yunis E. Phenotype variants, malignancy, and additional copies of $6 \mathrm{p}$ in retinoblastoma. Cancer Genet Cytogenet 1994:76:112-15.

81 Gallie BL, Campbell C, Devlin H, et al. Developmental basis of retinalspecific induction of cancer by RB mutation. Cancer Res 1999;59(Suppl):S1731-5

82 Chen D, Pajovic S, Duckett A, et al. Genomic amplification in retinoblastoma narrowed to 0.6 megabase on chromosome $6 p$ containing a kinesin-like gene, RBKIN. Cancer Res 2002;62:967-71.

83 Orlic M, Spencer CE, Wang L, et al. Expression analysis of $6 \mathrm{p} 22$ genomic gain in retinoblastoma. Genes Chromosomes Cancer 2006:45:72-82.

84 Grasemann C, Gratias S, Stephan H, et al. Gains and overexpression identify DEK and E2F3 as targets of chromosome 6p gains in retinoblastoma. Oncogene 2005;24:6441-9.

85 Schulten HJ, Gunawan B, Enders C, et al. Overrepresentation of $8 \mathrm{q}$ in carcinosarcomas and endometrial adenocarcinomas. Am J Clin Patho 2004; 122:546-51.

86 Buschges R, Weber RG, Actor B, et al. Amplification and expression of cyclin D genes (CCND1, CCND2 and CCND3) in human malignant gliomas. Brain Pathol 1999:9:435-42.

87 Plantaz D, Mohapatra G, Matthay KK, et al. Gain of chromosome 17 is the most frequent abnormality detected in neuroblastoma by comparative genomic hybridization. Am J Pathol 1997;150:81-9.

88 Brinkschmidt $\mathrm{C}$, Poremba $\mathrm{C}$, Christiansen $\mathrm{H}$, et al. Comparative genomic hybridization and telomerase activity analysis identify two biologically different groups of 4s neuroblastomas. Br J Cancer 1998;77:2223-9.

89 Woodfine K, Fiegler H, Beare DM, et al. Replication timing of the human genome. Hum Mol Genet 2004;13:191-202. 